\title{
Histone Methylation Regulates Memory Formation
}

\author{
Swati Gupta, ${ }^{1}$ Se Y. Kim, ${ }^{2}$ Sonja Artis, ${ }^{3}$ David L. Molfese, ${ }^{1}$ Armin Schumacher, ${ }^{4}$ J. David Sweatt, ${ }^{1}$ Richard E. Paylor, ${ }^{4,5}$ \\ and Farah D. Lubin ${ }^{1}$ \\ ${ }^{1}$ Evelyn F. McKnight Brain Institute, Department of Neurobiology, University of Alabama at Birmingham, Birmingham, Alabama 35294, ${ }^{2}$ Department of \\ Biochemistry and Cell Biology, Rice University, Houston, Texas 77005, ${ }^{3}$ Department of Medicinal Chemistry and Pharmocognosy, University of Illinois at \\ Chicago, Chicago, Illinois 60612, and ${ }^{4}$ Department of Molecular and Human Genetics, and ${ }^{5}$ Department of Neuroscience, Baylor College of Medicine, \\ Houston, Texas 77030
}

It has been established that regulation of chromatin structure through post-translational modification of histone proteins, primarily histone $\mathrm{H} 3$ phosphorylation and acetylation, is an important early step in the induction of synaptic plasticity and formation of long-term memory. In this study, we investigated the contribution of another histone modification, histone methylation, to memory formation in the adult hippocampus. We found that trimethylation of histone $\mathrm{H} 3$ at lysine 4 (H3K4), an active mark for transcription, is upregulated in hippocampus $1 \mathrm{~h}$ following contextual fear conditioning. In addition, we found that dimethylation of histone $\mathrm{H} 3$ at lysine 9 (H3K9), a molecular mark associated with transcriptional silencing, is increased $1 \mathrm{~h}$ after fear conditioning and decreased $24 \mathrm{~h}$ after context exposure alone and contextual fear conditioning. Trimethylated H3K4 levels returned to baseline levels at $24 \mathrm{~h}$. We also found that mice deficient in the H3K4-specific histone methyltransferase, Mll, displayed deficits in contextual fear conditioning relative to wild-type animals. This suggests that histone methylation is required for proper long-term consolidation of contextual fear memories. Interestingly, inhibition of histone deacetylases (HDACs) with sodium butyrate (NaB) resulted in increased $\mathrm{H} 3 \mathrm{~K} 4$ trimethylation and decreased H3K9 dimethylation in hippocampus following contextual fear conditioning. Correspondingly, we found that fear learning triggered increases in H3K4 trimethylation at specific gene promoter regions (Zif268 and $b d n f$ ) with altered DNA methylation and MeCP2 DNA binding. Zif268 DNA methylation levels returned to baseline at $24 \mathrm{~h}$. Together, these data demonstrate that histone methylation is actively regulated in the hippocampus and facilitates long-term memory formation.

\section{Introduction}

Experience-dependent transcriptional regulation is critical for the stabilization of long-term memory formation. While the role of transcription factors in the regulation of gene expression in memory has been the focus of intense research, an increasing amount of recent data have identified a role for chromatin remodeling in this process. Specifically, post-translational modifications of histones has been shown to be a mechanism for transcriptional regulation during long-term memory formation (Swank and Sweatt, 2001; Guan et al., 2002, 2009; Alarcón et al., 2004; Levenson et al., 2004a; Colvis et al., 2005; Kumar et al., 2005; Levenson and Sweatt, 2005; Chwang et al., 2006; Wood et al., 2006; Bredy et al., 2007; Fischer et al., 2007; Lubin et al., 2008).

The regulation of chromatin structure is complex. This is partly due to the N-terminal tails of histones which are highly accessible for enzymatic transformation and are sites for multiple

Received July 31, 2009; revised Jan. 15, 2010; accepted Jan. 21, 2010.

This work was supported by the National Institutes of Health (NS048811, MH082106, MH57014, NS37444, NS013546, AG031722, and NS057098), the Federation of American Societies for Experimental Biology, the National Alliance for Research on Schizophrenia and Depression, the Rotary Clubs Coins for Alzheimer's Research Trust Fund, and the Evelyn F. McKnight Brain Research Foundation. We thank members of the Lubin laboratory for their thoughtful comments, Dr. M. Han and the University of Alabama at Birmingham Genomics Core Facility for assistance in DNA sequencing, and Dr. A. Schumacher for providing the eed;MII mutant mice.

Correspondence should be addressed to Dr. Farah D. Lubin, Department of Neurobiology, University of Alabama at Birmingham, 1825 University Boulevard, Birmingham, AL 35294. E-mail: flubin@nrc.uab.edu.

DOI:10.1523/JNEUROSCI.3732-09.2010

Copyright $\odot 2010$ the authors $\quad 0270-6474 / 10 / 303589-11 \$ 15.00 / 0$ covalent post-translational modifications, including acetylation, phosphorylation, methylation, ubiquitination, and sumoylation (Peterson and Laniel, 2004; Berger, 2007). Histone modifications such as histone acetylation and phosphorylation facilitate the unraveling of DNA around the histone core resulting in the recruitment of the transcriptional machinery to mediate celland promoter-specific gene expression. However, other histone modifications such as histone methylation have different positive or negative effects on gene transcription depending on the amino acid residue modified and the number of methyl groups added (Berger, 2007).

The methylation of lysines can exist in three states: monomethylated, dimethylated, and trimethylated. Generally, transcriptionally silent regions contain dimethylation and trimethylation of histone $\mathrm{H} 3$ at lysine9 (H3K9) whereas active genes correlate with dimethylation and trimethylation of histone $\mathrm{H} 3$ at lysine 4 (H3K4) (Sims et al., 2003; Margueron et al., 2005; Martin and Zhang, 2005; Vermeulen et al., 2007). Specifically, dimethylation of $\mathrm{H} 3 \mathrm{~K} 9$ correlates with transcriptional silencing, and trimethylation of $\mathrm{H} 3 \mathrm{~K} 4$ is linked to active transcription (Santos-Rosa et al., 2002; Ng et al., 2003; Schneider et al., 2004). Recently histone methylation has been implicated in the regulation of chromatin structure in the nervous system (Tsankova et al., 2006; Huang and Akbarian, 2007; Huang et al., 2007; Kim et al., 2007). However, to date there have been no reports of histone methylation regulation in the nervous system functioning in the process of long-term memory storage. 
Thus in the present study, we sought to investigate histone $\mathrm{H} 3$ methylation as an experience-driven mechanism of transcriptional regulation in hippocampus during consolidation of fear-conditioned memories. We found that contextual fear conditioning induced both trimethylation of $\mathrm{H} 3 \mathrm{~K} 4$ and dimethylation of $\mathrm{H} 3 \mathrm{~K} 9$ in hippocampus, suggesting active increases in gene expression and gene repression during memory formation. Interestingly, treatment of animals with the histone deacetylase (HDAC) inhibitor sodium butyrate $(\mathrm{NaB})$ elevated trimethylation of $\mathrm{H} 3 \mathrm{~K} 4$ and decreased dimethylation of $\mathrm{H} 3 \mathrm{~K} 9$. This suggests that histone acetylation is intricately linked to histone methylation in hippocampus during consolidation of fearconditioned memories. We also found that heterozygous deletion of a known regulator of histone methylation, Mll, led to significant deficits in memory consolidation. Finally, we found that fear conditioning triggered increases in trimethylation of $\mathrm{H} 3 \mathrm{~K} 4$ at the Zif268 gene which were associated with altered DNA methylation at this gene promoter. Together, these observations implicate experience-driven alteration of histone methylation in hippocampus as a mechanism contributing to long-term memory formation.

\section{Materials and Methods}

Animals. Young adult, male Sprague Dawley rats (250-300 g) were used for all experiments with the exception of the Mll;eed mutant mice which were created as previously described by Kim et al. (2007). Briefly, the eed-null allele used in this study contained an $\mathrm{N}$-ethyl- $\mathrm{N}$-nitrosoureainduced L290P substitution in the second WD motif (Schumacher et al., 1996) and was maintained on a mixed genetic background largely derived from 101/R1 and C3Hf/R1. The mutant Mll allele used in this study harbors a lacZ insertion in the third exon, resulting in a truncated protein (Yu et al., 1995). The mutant Mll allele was maintained on a mixed background with contributions from C57BL/6J, C3H/HeJ, and FVB/NJ. Experiments encompassed single and double heterozygous animals derived from intercrosses of eed and Mll single mutant mice. Homozygosity for the $r d$ mutation was excluded by PCR. Animals were housed under light/dark $12 \mathrm{~h} / 12 \mathrm{~h}$ and allowed access to rodent chow and water ad libitum. Five days before experiments, animals were handled for 3-5 min each and allowed to acclimate to laboratory condition. All procedures were performed with the approval of the University of Alabama at Birmingham Institutional Animal Care and Use Committee and according to national guidelines and policies.

Fear conditioning training paradigm. Rats were transported to the laboratory at least $30 \mathrm{~min}$ before fear conditioning. Fear-conditioned animals were allowed to explore the chamber for $2 \mathrm{~min}$, after which they received a series of three electric shocks $(1 \mathrm{~s}, 0.5 \mathrm{~mA})$ at 2 min intervals. As controls, context-exposed or latent inhibition plus fear-conditioned animals were also placed in the novel training chambers. Context-exposed animals were placed in the novel training chamber for $7 \mathrm{~min}$ without receiving the footshock. Latent inhibition plus fear-conditioned animals were pre-exposed to the context for $2 \mathrm{~h}$ before the same 7 min training protocol was administered as described for the fear-conditioned animals. In all shocked groups the animals were allowed to explore the novel context (training chamber) for an additional $1 \mathrm{~min}$ after the receiving the final footshock before being returned to their home cage. Freezing behavior was recorded using Video Freeze software (Med Associates). Another group of age-matched animals that were handled by the experimenter but did not receive any experimental manipulations were used as naive controls in all experiments.

Behavioral testing in eed $\times$ Mll mice. Exploratory activity, motor function, and sensorimotor processing were performed as described previously (Paylor et al., 2006). Behavioral experiments of eed $\times$ Mll investigation used 91 female mice at $8-12$ weeks of age $\left(n=29 \mathrm{eed}^{+/+}\right.$; $\mathrm{Mll}^{+/+}, 26 \mathrm{eed}^{+/-} ; \mathrm{Mll}^{+/+}, 18 \mathrm{eed}^{+/+} ; \mathrm{Mll}^{+/-}$, and $\left.18 \mathrm{eed}^{+/-} ; \mathrm{Mll}^{+/-}\right)$. In the contextual fear paradigm (McIlwain et al., 2001), mice were placed in a chamber and after $2 \mathrm{~min}$ the mice received two conditioned stimulus (CS; $80 \mathrm{~dB}$ auditory sound, $30 \mathrm{~s}$ )- unconditioned stimulus (US; $0.7 \mathrm{~mA}$ mild footshock, 2 s) pairings separated by $2 \mathrm{~min}$. Twenty-four hours later, the mice were assayed for freezing behavior to determine associative learning of the footshock with the contextual cues, which constitutes the training environment, and the discretely paired auditory sound. On test day, the amount of freezing during the $3 \mathrm{~min}$ pre-CS period was subtracted from the freezing during the $3 \mathrm{~min}$ CS presentation.

Isolation of area CA1. Animals were killed using a rodent guillotine. The brain was immediately immersed in oxygenated $\left(95 \% / 5 \% \mathrm{O}_{2} / \mathrm{CO}_{2}\right)$ ice-cold cutting saline containing the following (in mM): 110 sucrose, 60 $\mathrm{NaCl}, 3 \mathrm{KCl}, 1.25 \mathrm{NaH}_{2} \mathrm{PO}_{4}, 28 \mathrm{NaHCO}_{3}, 0.5 \mathrm{CaCl}_{2}, 7 \mathrm{MgCl}_{2}, 5$ glucose, 0.6 ascorbate. The whole hippocampus was then removed and area CA1 was dissected away from other hippocampal subfields under a dissecting microscope. Once isolated, area CA1 was frozen on dry ice then stored at $--80^{\circ} \mathrm{C}$ until processed.

Histone extraction. Histone extractions were performed as in Lubin et al. (2007). Briefly, all procedures were performed on ice, and all solutions were chilled to $4^{\circ} \mathrm{C}$ before use unless otherwise indicated. All centrifugation steps were performed at $4^{\circ} \mathrm{C}$. Hippocampal tissue was Dounce homogenized in ice-cold homogenization buffer containing the following (in $\mathrm{mm}$ ): 250 sucrose, 50 Tris, $\mathrm{pH} 7.5,25 \mathrm{KCl}, 0.5$ phenylmethylsulfonyl fluoride, $1 \%$ protease inhibitor mixture (Sigma), $0.9 \mathrm{Na}^{+}$-butyrate using no more than six strokes of a glass pestle (Kontes Glass). Hippocampal tissue homogenates were centrifuged at 7700 ' $g$ for $1 \mathrm{~min}$ and the supernatant (cytoplasmic fraction) was aspirated. The pellet (nuclear fraction) was then resuspended in $0.5 \mathrm{ml}$ of $0.4 \mathrm{~N} \mathrm{H}_{2} \mathrm{SO}_{4}$, incubated for $30 \mathrm{~min}$ and centrifuged at $14,000^{\prime} \mathrm{g}$ for $10 \mathrm{~min}$. The supernatant was transferred to a fresh tube, and proteins were precipitated with the addition of $250 \mu \mathrm{l}$ of $100 \%$ trichloroacetic acid containing $4 \mathrm{mg} / \mathrm{ml}$ deoxycholic acid $\left(\mathrm{Na}^{+}\right.$ salt, Sigma) for $30 \mathrm{~min}$. Acid extracted histone proteins were then collected by centrifugation at 14,000 ' $g$ for $30 \mathrm{~min}$. The supernatant was discarded, and the protein pellet was washed with $1 \mathrm{ml}$ of acidified acetone $(0.1 \% \mathrm{HCl})$ followed by $1 \mathrm{ml}$ of acetone for $5 \mathrm{~min}$ each. Protein precipitates were collected between washes by centrifugation $(14,000$ ' $g$, $5 \mathrm{~min}$ ). The resulting purified histone proteins were resuspended in $10 \mathrm{mM}$ Tris ( $\mathrm{pH} 8$ ) and stored at $-80^{\circ} \mathrm{C}$ until processed for Western blotting.

Western blotting. Protein concentrations for each sample were determined using a DC protein assay (Bio-Rad). Aliquots of sample were then normalized to $\sim 2 \mu \mathrm{g} / \mu \mathrm{l}$. Laemmli sample buffer (final concentration: 6.25 mм Tris, pH 6.8, 2\% SDS, 10\% glycerol, 1.25\% 2-mercaptoethanol, $0.1 \%$ bromophenol blue] was added to histone samples before performing SDS-PAGE. SDS-PAGE gels consisted of a $12 \%$ acrylamide resolving gel overlaid with a $4 \%$ acrylamide stacking gel. Histone proteins were transferred to polyvinylidene difluoride (PVDF) membranes for immunoblotting which consisted of incubating PVDF membranes in primary antibodies for $1 \mathrm{~h}$ at room temperature or overnight at $4^{\circ} \mathrm{C}$ followed by incubation with a horseradish peroxidase-conjugated secondary antibody for $2 \mathrm{~h}$ at room temperature. Detection of immunolabeled histone proteins was facilitated via electrogenerated chemiluminescence (ECL; GE Healthcare; SuperSignal, Pierce) and exposure to BioMax X-Ray film (Kodak Scientific Imaging Systems) and digitized (Epson Perfection 1240U).

Antibodies. The primary antibodies used, and their dilutions, were as follows: anti-H3K4me3 (1:1000, Millipore Biotechnology), antiH3K9me2 (1:1000, Millipore Biotechnology), and anti-H3 (1:1000, Millipore Biotechnology). The host for all primary antibodies was rabbit. The secondary antibodies were horseradish peroxidase-conjugated goat anti-IgG heavy and light chain (Jackson ImmunoResearch).

Chromatin immunoprecipitation assay. Chromatin immunoprecipitation (ChIP) analysis was performed as previously described by Lubin et al. (2007). Briefly, the CA1 regions of hippocampus were microdissected and held in ice-cold PBS solution containing protease inhibitors [1 mM phenylmethylsulfonyl fluoride, $1 \mu \mathrm{g} / \mathrm{ml}$ of protease inhibitor mixture and phosphatase inhibitors $\left(1 \mathrm{~mm} \mathrm{Na}_{3} \mathrm{VO}_{4}\right.$ and $\left.\left.20 \mathrm{~mm} \mathrm{NaF}\right)\right]$. Hippocampal tissue was immediately incubated in $1 \%$ formaldehyde in PBS at $37^{\circ} \mathrm{C}$ for $10 \mathrm{~min}$. Hippocampal tissue was homogenized in SDS lysis buffer (50 mm Tris, pH 8.1, 10 mm EDTA, 1\% SDS). Chromatin was sheared using a Branson Sonifier 250 at 1.5 power and constant duty cycle. Lysates were centrifuged to pellet debris and then diluted 1:10 in ChIP dilution buffer (16.7 mm Tris, $\mathrm{pH}$ 8.1, 0.01\% SDS, 1.1\% Triton 
X-100, $167 \mathrm{~mm} \mathrm{NaCl}, 1.2 \mathrm{~mm}$ EDTA). Immunoprecipitations were performed at $4^{\circ} \mathrm{C}$ overnight with primary antibodies (anti-H3K4me3 or $\mathrm{MeCP} 2$ ) or no antibody (control). Immune complexes were collected with an protein A-agarose bead/salmon sperm slurry and sequentially washed with low-salt buffer ( $20 \mathrm{~mm}$ Tris, $\mathrm{pH}$ 8.0, $0.1 \%$ SDS, $1 \%$ Triton $\mathrm{X}-100,2$ mм EDTA, $150 \mathrm{~mm} \mathrm{NaCl}$ ), high-salt buffer (20 mм Tris, pH 8.1, $0.1 \%$ SDS, $1 \%$ Triton X-100, 500 mм NaCl, 1 mm EDTA), LiCl immune complex buffer $(0.25 \mathrm{~m} \mathrm{LiCl}, 10 \mathrm{~mm}$ Tris, $\mathrm{pH} 8.1,1 \%$ deoxycholic acid, $1 \%$ IGEPAL-CA630, $500 \mathrm{~mm} \mathrm{NaCl}, 2$ mm EDTA), and TE buffer. Immune complexes were extracted in $1^{\prime}$ TE containing $1 \%$ SDS, and protein-DNA cross-links were reverted by heating at $65^{\circ} \mathrm{C}$ overnight. After proteinase $\mathrm{K}$ digestion $\left(100 \mu \mathrm{g} ; 2 \mathrm{~h}\right.$ at $\left.37^{\circ} \mathrm{C}\right)$, DNA was extracted by phenol/chloroform/isoamyl alcohol and then ethanol precipitated. Immunoprecipitated DNA was subjected to quantitative real-time PCR using primers using primers specific for 150-200 bp segments corresponding to promoters upstream of the rat Bdnf or Zif268: Bdnf promoter 1 sense, 5'-TGAGAAGTTGTGGGACCGCATA-3'; antisense, 5' -CGTCCTCTTCCCTTGGCTTTTT-3'; Bdnf promoter 4 sense, 5' -GTGGAGGAGAGGTGCCTTTTGA-3'; antisense, 5'-GTCCTCTGGGGACCATTTACCC-3'; Zif268 (ChIP 1) sense, 5' -ATGGGCTGTTAGGGACAGTG-3'; antisense, 5' -TTGGGGATTTAGCTCAGTGG-3'; Zif268 (ChIP 2) sense, $5^{\prime}$-CTCCCTCACTGCGTCTAAGG-3'; antisense, 5' -CCTAAAGAGGGGGACTTTGC- $3^{\prime}$. The cumulative fluorescence for each amplicon was normalized to input amplification.

Methylation-specific real-time PCR analysis. DNA was isolated from hippocampal tissue, purified and processed for bisulfite modification. For all our methylation-specific real-time PCR (MSP) data, we performed bisulfite treatment of genomic DNA an average of 5-6 times. Bisulfite treatment of genomic DNA converts cytosine to uracil, but leaves methylated 5'cytosines unchanged. Quantitative real-time PCR was used to determine the DNA methylation status of the $b d n f$ gene. Methylation-specific PCR primers were designed using Methprimer software (http://www.urogene.org/methprimer/) (Li and Dahiya, 2002). Methylation and unmethylated-specific PCR primers were designed to target putative $\mathrm{CpG}$ islands detected in silico in promoter or nonpromoter regions of the Zif268 gene. Detection of CpG islands ( $\$ 200 \mathrm{bp}$ ) within Zif268 DNA was performed with the following primer sets. For CpG island region 1; methylated Zif268 sense, 5' -ATTGCGGGGAAGGTTTAGGTC-3'; antisense, 5' -TATATTCCGAAAACCCCAAACG-3'; unmethylated Zif268 sense, 5'-ATTGTGGGGAAGGTTTAGGTTG-3'; antisense, $5^{\prime}$-ATATTCCAAAAACCCCAAACAC-3'. For CpG island 2; methylated Zif268 sense, 5' -TTTAGGATGACGGTTGTAGAATTTC-3'; antisense, 5' -GCGTAAAACTAAACGCTCCG-3'; unmethylated Zif268 sense, $5^{\prime}$-GGATGATGGTTGTAGAATTTTGG-3'; antisense, $5^{\prime}$-CAAACACATAAAACTAAACACTCCA- $3^{\prime}$. We also evaluated $\beta$-tubulin-4 DNA after context exposure or contextual fear conditioning and found no significant alterations in unmethylated $\beta$-tubulin-4 DNA. Thus, we used unmethylated $\beta$-tubulin-4 levels for normalization of Zif268 DNA methylation in the studies presented here. $\beta$-Tubulin- 4 sense, $5^{\prime}$ GGAGAGTAATATGAATGATTTGGTG-3'; antisense, $5^{\prime}$-CATCTCAACTTTCCCTAACCTACTTAA-3'. PCRs were in a iQ5 real-time PCR system (Bio-Rad) using the following cycling conditions: $95^{\circ} \mathrm{C}$ for $3 \mathrm{~min}$, 40 cycles of $95^{\circ} \mathrm{C}$ for $15 \mathrm{~s}$ and $58-60^{\circ} \mathrm{C}$ for $1 \mathrm{~min}$. Detection of the fluorescent products occurred at the end of the $15 \mathrm{~s}$ temperature step. Samples were normalized to $\beta$-tubulin- 4 and the comparative $\mathrm{Ct}$ method was used to calculate differences in gene expression between samples (Livak and Schmittgen, 2001).

Bisulfite DNA sequencing PCR. Bisulfite-treated samples (as described above) were amplified by primers that amplify the same region of $b d n f$ exon IV DNA, but independent of methylation status. The thermocycler protocol involved an initial denaturation cycle $\left(5 \mathrm{~min}, 95^{\circ} \mathrm{C}\right), 50$ cycles of denaturation $\left(1 \mathrm{~min}, 95^{\circ} \mathrm{C}\right)$, annealing $\left(1 \mathrm{~min}, 60^{\circ} \mathrm{C}\right)$, and extension $(1$ $\min , 72^{\circ} \mathrm{C}$ ), followed by a final extension cycle $\left(5 \mathrm{~min}, 72^{\circ} \mathrm{C}\right)$ terminating at $4^{\circ} \mathrm{C}$ resulting in a $258 \mathrm{bp}$ PCR product for exon IV. Bisulfite DNA sequencing PCR (BSP) primer pairs used for the assessment of Zif268 cytosine residues within $\mathrm{CpG}$ island region 1 were as follows; Zif 2568 sense, 5' -TTGTGAAGGAAGTGTTATTTTG-3'; antisense, 5' -CCAATCTAATAACCCCAAACTT-3'. The BSP products were then purified using a gel extraction kit (Qiagen), and sequenced using the reverse primer at the University of Alabama at Birmingham Genomics Core Facility of the Heflin Center for Human Genetics (http://www.heflingenetics. uab.edu). The percentage methylation of each $\mathrm{CpG}$ site within the region amplified was determined by the ratio between peaks values of $G$ and $A$ $(\mathrm{G} /[\mathrm{G}+\mathrm{A}])$, and these levels on the electropherogram were determined using Chromas software.

Statistical analysis. Behavioral data were analyzed with two-tailed unpaired $t$ tests. Post hoc comparisons after one-way ANOVA were made using Tukey post hoc test where appropriate. Data for Mll;eed mutant mice were analyzed using individual one-way ANOVA with LSD post hoc and simple-effects tests where appropriate for the context test and the CS test. Follow-up comparisons were made using least significance difference test. SPSS 10.0 software was used for statistical analysis of the data. All Western blots were quantified by densitometry (Scion) and GraphPad Prism software was used for statistical analysis of the data. For studies involving the assessment of histone or DNA methylation and mRNA levels were analyzed by two-tailed one-sample $t$ tests when appropriate. Differences in BSP data were analyzed by two-way ANOVA with Bonferroni's post hoc test. Data are shown as the mean \pm SEM. Significance for all tests was set at $p \mathfrak{E} 0.05$.

\section{Results}

Regulation of histone $\mathrm{H} 3$ methylation in hippocampus during associative and episodic memory formation

To begin exploring the potential role for histone methylation in memory formation we investigated whether contextual fear conditioning as an associative learning event triggers altered histone methylation within the hippocampus. For behavioral studies animals were fear conditioned in a novel context (training chamber) with a training protocol consisting of three $1 \mathrm{~s}, 0.5 \mathrm{~mA}$ shocks at 2 min shock intervals (Fig. 1A). As a control for our biochemical studies, we first confirmed that the context-plusshock pairing produced an associative memory. As expected, $24 \mathrm{~h}$ after fear conditioning, re-exposing the animals to the training chamber without the footshock triggered recall of the associative memory, as measured by freezing behavior (Fig. $1 B$ ). As an additional control, novel context exposure alone produced no significant freezing when the animals were replaced in the training chamber (Fig. $1 B$ ).

To evaluate whether histone methylation was altered in response to contextual learning, histone extracts were prepared from area CA1 of hippocampus $1 \mathrm{~h}$ after training (Fig. $1 A$ ). Thus, we evaluated histone $\mathrm{H} 3$ methylation at lysine 4 (K4) as an active marker of transcription and observed a significant increase in trimethylated H3K4 levels in the hippocampus $1 \mathrm{~h}$ after contextual fear conditioning compared with naive controls (Fig. 1C). No changes in trimethylated H3K4 levels were observed with context exposure alone (Fig. 1C). These results suggest that $\mathrm{H} 3 \mathrm{~K} 4$ trimethylation is regulated in hippocampus after associative fear conditioning training and are consistent with prior observations that active transcription occurs during consolidation of associative contextual memories. These observations also implicate histone methylation as a potential positive regulator of gene transcription in memory consolidation.

We also examined whether or not contextual fear conditioning alters methylation of histone $\mathrm{H} 3$ at lysine9 (K9), a repressive marker of transcription, in area CA1 of the hippocampus. Western blotting analysis revealed that $1 \mathrm{~h}$ after contextual fear conditioning $\mathrm{H} 3 \mathrm{~K} 9$ dimethylation significantly increased in area CA1 of the hippocampus (Fig. 1D). Interestingly, context exposure alone produced similar increases in dimethylated H3K9 levels in area CA1 of hippocampus relative to naive control animals (Fig. 1D). These findings suggest that $\mathrm{H} 3 \mathrm{~K} 9$ dimethylation is triggered in hippocampus with both novel context learning and associative contextual learning of fear. Together, these results are 
A
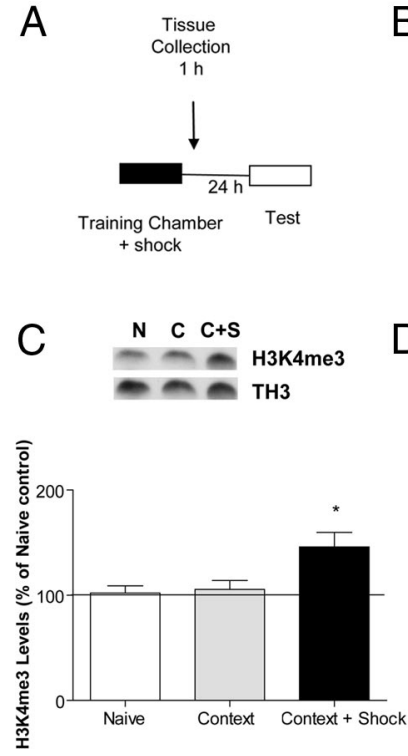

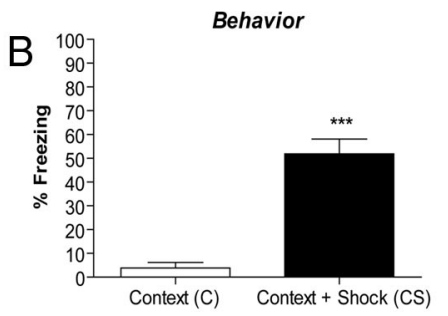

D
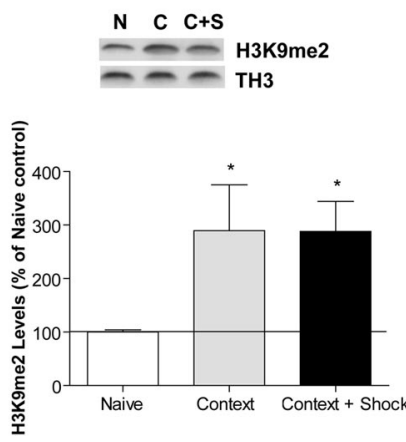

Figure 1. Contextual fear conditioning alters histone $\mathrm{H} 3$ methylation in hippocampus. $\boldsymbol{A}$, Outline of experimental design used with results displayed in $\boldsymbol{B}-\boldsymbol{D}$. $\boldsymbol{B}$, Twenty-four hours after fear conditioning training, animals were exposed to the context and freezing behavior was measured. Animals exposed to the novel training chamber followed by three consecutive footshocks (context plus shock) displayed increased freezing when compared with animals exposure to the context alone (Student's two-tailed $t$ test, $t_{(11)}=6.794, p<0.0001, n=6-7$ / group). ${ }^{* *} p$ value significant compared with context alone. $C$, Animals were fear conditioned and area $\mathrm{CA} 1$ of hippocampus was isolated at $1 \mathrm{~h}$ after training. A significant increase in histone $\mathrm{H} 3$ trimethylation at lysine 4 (H3K4me3) was observed after fear conditioning $(\mathrm{C}+\mathrm{S})$ when compared with animals that were handled without exposure to naive $(\boldsymbol{N})$ or context-exposed $(C)$ animal cohorts (one-way ANOVA with Tukey's multiple-comparison test, $F_{(2,28)}=5.560$, $p=0.0098, n=9-10 /$ group). ${ }^{*} p<0.05$ compared with naive-treated animals. D, There was a significant increase in regulation of histone $\mathrm{H} 3$ dimethylation at lysine 9 (H3K9me2) $1 \mathrm{~h}$ after either fear conditioning or context exposure alone when compared with naive-treated animal cohorts (one-way ANOVA with Tukey's multiple-comparison test, $F_{(2,35)}$ $=5.978, p=0.0061, n=9-16 /$ group). ${ }^{*} p<0.05$ compared with naive-treated animals. Solid line represents normalized naive control levels. Error bars are SEM.

consistent with the idea that histone-methylation-dependent active repression of transcription plays a role in the consolidation of contextual memories. It is interesting that context exposure alone triggered only the transcription-suppressing $\mathrm{H} 3 \mathrm{~K} 9$ dimethylation mark and not the transcription-activating H3K4 mark (see above), implying that the H3K4 mark may be an associativelearning-specific signal.

Next, we determined whether regulation of hippocampal histone $\mathrm{H} 3$ methylation triggered with learning about the context or with associative contextual fear conditioning is a dynamic process. To address this, area CA1 of hippocampus was removed from animals $24 \mathrm{~h}$ after training and Western blotting performed for histone $\mathrm{H} 3$ methylation that serve as activation (H3K4) or repressor (H3K9) markers of gene transcription (Fig. 2A). All groups were compared with naive-handled animals that were not exposed to the training chamber. Twenty-four hours after training (without replacing animals into the training context) Western blotting analysis revealed no changes in $\mathrm{H} 3 \mathrm{~K} 4$ trimethylation in hippocampus after fear conditioning (Fig. $2 \mathrm{~B}$ ). In addition, levels of trimethylated $\mathrm{H} 3 \mathrm{~K} 4$ were unchanged $24 \mathrm{~h}$ after context exposure alone when compared with naive animal controls (Fig. $2 B$ ). These results suggest that trimethylation of $\mathrm{H} 3 \mathrm{~K} 4$ is reversible, allowing the $\mathrm{H} 3 \mathrm{~K} 4$ trimethylation state necessary for memory consolidation to return to basal levels after transient activation. Furthermore, these findings support the idea that a histone de-

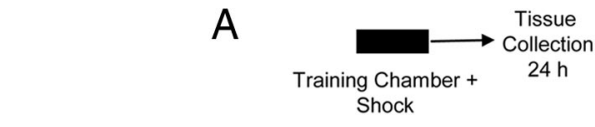

B
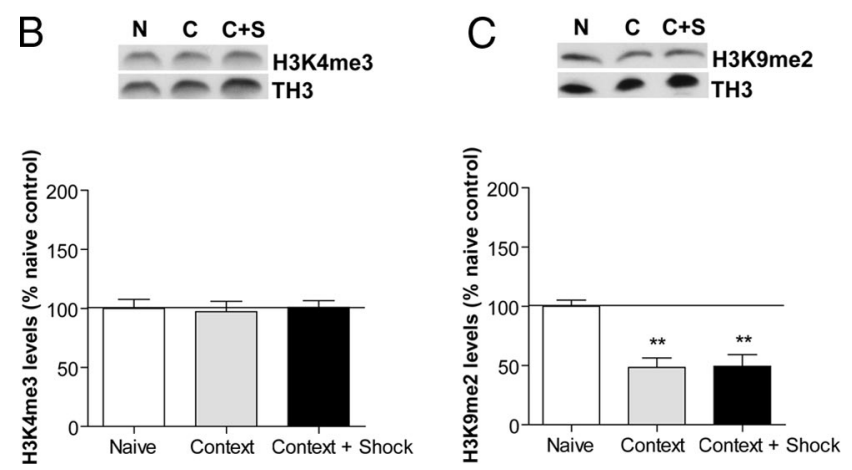

Figure 2. Histone H3 dimethylation persists in hippocampus after contextual fear conditioning. $A$, Animals were fear conditioned and area CA1 of hippocampus was isolated at $24 \mathrm{~h}$ after training. Results are displayed in $\boldsymbol{B}$ and $\boldsymbol{C}$. $\boldsymbol{B}$, Twenty-four hours after fear conditioning histone $\mathrm{H} 3$ trimethylation at lysine 4 ( $\mathrm{H} 3 \mathrm{~K} 4 \mathrm{me} 3$ ) levels returned to baseline in area $\mathrm{CA} 1$ in hippocampus (one-way ANOVA with Tukey's multiple-comparison test, $F_{(2,12)}=0.06002, p=0.9421, n=$ 4-5/group). C, Histone H3 dimethylation (H3K9me2) decreased $24 \mathrm{~h}$ following both fear conditioning $(\boldsymbol{C}+S)$ and context exposure alone $(\boldsymbol{C})$ relative to naive control $(\boldsymbol{N})$ (one-way ANOVA with Tukey's multiple-comparison test, $F_{(2,12)}=8.917, p=0.006, n=4-5 /$ group). ${ }^{* *} p<$ 0.01 compared with naive-treated animals. Solid line represents normalized naive control levels. Error bars are SEM.

methylase does exist for active demethylation of trimethylated $\mathrm{H} 3 \mathrm{~K} 4$ induced in hippocampus after associative fear conditioning training.

Having established that the increase in $\mathrm{H} 3 \mathrm{~K} 4$ trimethylation with fear conditioning was reversible, we then sought to determine whether or not the effect of contextual fear conditioning on H3K9 dimethylation was also plastic. Surprisingly, we found that H3K9 dimethylation significantly decreased $24 \mathrm{~h}$ after fear conditioning compared with naive controls (Fig. $2 \mathrm{C}$ ). We also observed a decrease in $\mathrm{H} 3 \mathrm{~K} 9$ dimethylation $24 \mathrm{~h}$ after exposure to context alone compared with naive animal controls (Fig. 2C). These results indicate that learning about the context or fear conditioning to the context has effects on $\mathrm{H} 3 \mathrm{~K} 9$ dimethylation in hippocampus that persist at least $24 \mathrm{~h}$. These findings are the first evidence to indicate a persistent change in a hippocampal histone modification following learning, lasting well beyond the $2-4 \mathrm{~h}$ memory consolidation phase.

The results obtained thus far suggest that $\mathrm{H} 3 \mathrm{~K} 4$ trimethylation is induced by formation of an associative long-term memory wherein an animal associates a novel context with a footshock. However, it is also possible that the regulation of hippocampal H3K4 trimethylation was due to a stress response to the footshock alone in the absence of associative memory formation. Therefore, a latent inhibition training paradigm was used to determine whether this event contributed to the regulation of $\mathrm{H} 3 \mathrm{~K} 4$ trimethylation in hippocampus after fear conditioning.

The latent inhibition training protocol consists of preexposing the animal to a novel context (training chamber) for a long period of time before administering the unconditioned stimulus (footshock). This form of contextual learning is unique in that the animal does not form a strong association between the unconditioned stimulus and the novel context, making the actual latent inhibition training paradigm context-specific (Lubow and Josman, 1993; Atkins et al., 1998). Therefore, during a latent inhibition contextual learning the animal forms a spatial memory that attenuates the formation of an associative contextual fear 
A

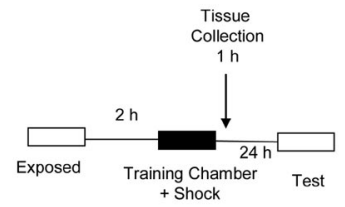

B
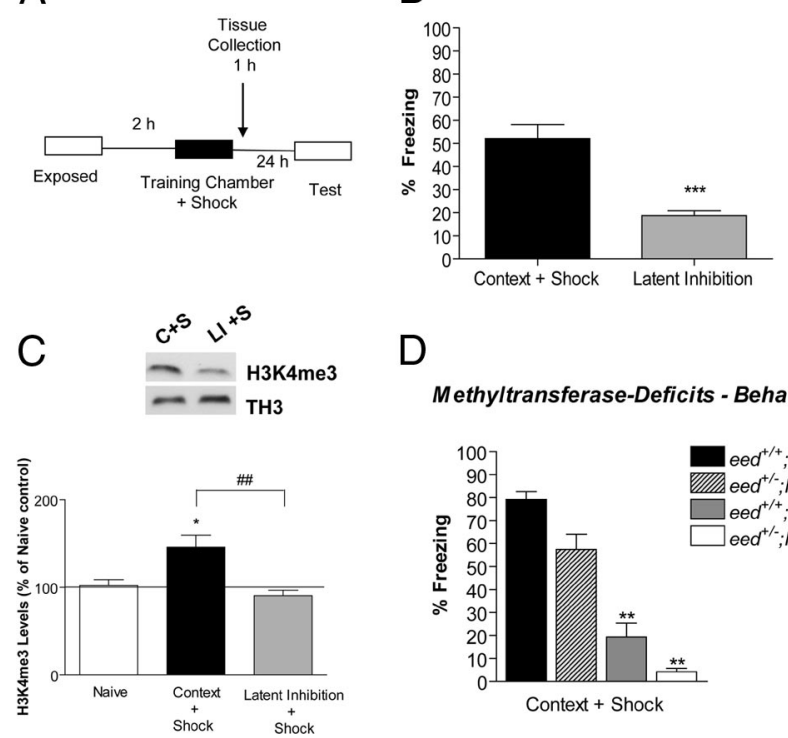

$\mathrm{D}$

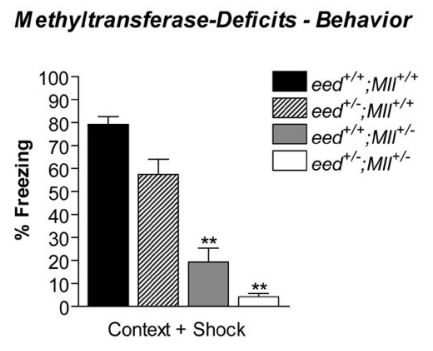

Figure 3. Regulation of histone $\mathrm{H} 3$ trimethylation in hippocampus after contextual fear conditioning requires proper timing. $\boldsymbol{A}$, Diagram of experimental design displaying the timeline for when animals were exposed to the contextual fear conditioning or the latent inhibition training paradigm with results displayed in $\boldsymbol{B}$ and $\boldsymbol{C}$. $\boldsymbol{B}$, Animals exposed to the latent inhibition (latent inhibition plus shock; LI+S) training paradigm displayed significantly less freezing behavior when compared with animals exposed to the fear conditioning learning paradigm (context plus shock; $C+S$ ) (one-way ANOVA with Tukey's multiple-comparison test, $F_{(2,26)}=$ 8.377, $p=0.0017, n=8-10$ /group). ${ }^{*} p<0.05$ compared with naive-treated animals, ${ }^{\# \#} p<0.01$ compared with $\mathrm{C}+\mathrm{S}$. C, Histone $\mathrm{H} 3$ trimethylation levels in area CA1 of hippocampus was significantly greater $1 \mathrm{~h}$ after fear conditioning compared with latent inhibition training. Solid line represents normalized naive control levels. $\boldsymbol{D}$, Deficits in behavioral memory formation with genetic knock-out of histone methylation modifying enzymes. The figure depicts the level of freezing for four genotypes $24 \mathrm{~h}$ following fear conditioning training. A $24 \mathrm{~h}$ test after fear conditioning revealed significantly decreased levels of freezing in eed ${ }^{+/+}$; $M I^{+/-}$and eed ${ }^{+/-} ; M I^{+/-}$mice compared with wild-type littermates $\left(F_{(3,36)}=32.41\right.$, $p<0.0001, n=8-10 /$ group, all comparisons to wild-type littermates $p<0.015)$. Error bars are SEM.

memory. Nevertheless, in this protocol the animal still receives the identical footshock used for associative fear conditioning training.

Animals were placed into the novel training context (training chamber) $2 \mathrm{~h}$ before receiving the three-shock context fear conditioning training (Fig. 3A). The animals were then returned to their home cages. Twenty-four hours later, the animals were reexposed to the training chamber with no footshock (test). Latent inhibition fear conditioning inhibited the associative contextual fear memory as assessed by freezing behavior (Fig. 3B). We also found that the increase in hippocampal $\mathrm{H} 3 \mathrm{~K} 4$ trimethylation normally observed $1 \mathrm{~h}$ after fear conditioning was blocked with the latent inhibition paradigm compared with naive controls (Fig. 3C). These results suggest that the regulation of $\mathrm{H} 3 \mathrm{~K} 4$ trimethylation after training was selective for the formation of robust associative contextual fear memories.

\section{Mll (H3K4-specific methyltransferase) mutant mice have a deficit in long-term contextual fear memory}

A number of enzymes for methylating or demethylating histones have recently been discovered (summarized in Allis et al., 2007). While few pharmacological agents are currently known to specifically affect these enzymes, genetic knock-out of these chromatin-modifying enzymes or their complexing partners allows us to further elucidate their specific role in learning

and memory. Recently, Kim and colleagues reported altered patterns of histone methylation in $\mathrm{eed}^{+/-} ; \mathrm{Mll}^{+/-}$mice (Kim et al., 2007). Eed interacts directly with the histone-lysine methyltransferase Ezh2 to target H3K27 or H1K26 (Kuzmichev et al., 2004) and interacts with HDAC 1 and 2 (van der Vlag and Otte, 1999). Mll also interacts with HDAC 1 and 2 (Xia et al., 2003) and acts as an H3K4-specific methyltransferase (Milne et al., 2002).

To further assess the role of regulation of histone methylation in the process of memory consolidation, we assessed fear memory in eed and Mll and single and double mutant mice (Paylor et al., 1994; McIlwain et al., 2001; Kim et al., 2007) comparing their behavior to wild-type littermate control animals using an associative contextual fear paradigm. We found significant differences between genotypes during the context behavior test (Fig. $3 D$ ). In these comparisons we found that $\mathrm{eed}^{+/+} ; \mathrm{Mll}^{+/-}$and $\mathrm{eed}^{+/-} ; \mathrm{Mll}^{+/-}$animals displayed significantly reduced freezing compared with wild-type littermates (all comparisons $p<$ $0.015)$. The effect on freezing behavior is stronger in heterozygote Mll mice compared with heterozygote eed mice. This is consistent with the idea that Mll is a $\mathrm{H} 3 \mathrm{~K} 4$-specific methyltransferase whereas Eed is a general component of the methyltransferase complex. Together, these results suggest in-part that the H3K4specific methyltransferase, Mll, is essential for hippocampaldependent long-term memory formation. Additionally, we assessed cued fear conditioning in $\mathrm{eed}^{+/-} ; \mathrm{Mll}^{+/+}$, eed ${ }^{+/+}$; $\mathrm{Mll}^{+/-}$, and in $\mathrm{eed}^{+/-} ; \mathrm{Mll}^{+/-}$mice and found no statistically significant differences in freezing behavior among genotypes $\left(F_{(3,63)}=0.664, p=0.57\right)$ (supplemental Fig. $1 \mathrm{H}$, available at www.jneurosci.org as supplemental material). Thus, eed and Mll are important for hippocampus-mediated learning and memory. Together, these findings indicate regulation of hippocampal histone methylation as a molecular mechanism underlying proper memory formation.

As additional behavioral controls, exploratory activity, motor function, and sensorimotor processing were assayed in eed and Mll mutant mice. While eed single heterozygous mice exhibited largely normal behavioral responses, $M l l$ single heterozygotes as well as double heterozygotes exhibited defects in some tests of motor function (supplemental Fig. $1 F$, available at www. jneurosci.org as supplemental material). In contrast, exploratory activity, anxiety-related responses, acoustic startle, and prepulse inhibition were normal (supplemental Fig. 1, available at www.jneurosci.org as supplemental material).

\section{Inhibition of histone deacetylases enhances histone} methylation in hippocampus

Recent studies have revealed that the methylation state of histone $\mathrm{H} 3$ is directly linked to the hyperacetylated state of the histone $\mathrm{H} 3$ $\mathrm{N}$-terminal tail in vitro (Zhang et al., 2004). In these studies, Zhang and colleagues report a synchronous relationship between hyperacetylated histone $\mathrm{H} 3$ at lysine- 9 and hypermethylated histone $\mathrm{H} 3$ at lysine-4. Thus, we hypothesized that enhancing histone acetylation via HDAC inhibition might result in an enhancement in histone methylation as well.

To this end, we investigated whether treatment with the HDAC inhibitor sodium butyrate $(\mathrm{NaB})$ might enhance the methylated state of histones in hippocampus during memory formation (Fig. 4A). We first confirmed the reported effect of HDAC inhibition on long-term memory formation. We found that $24 \mathrm{~h}$ after the training period, NaB-treated animals displayed significantly more freezing behavior than vehicle-treated controls (Fig. $4 B$ ). These results are in agreement with previous reports of the effect of HDAC inhibition on long-term memory 
A

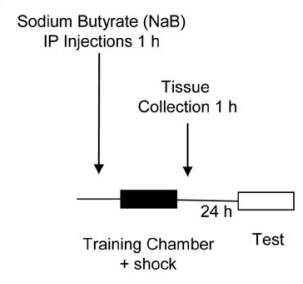

C
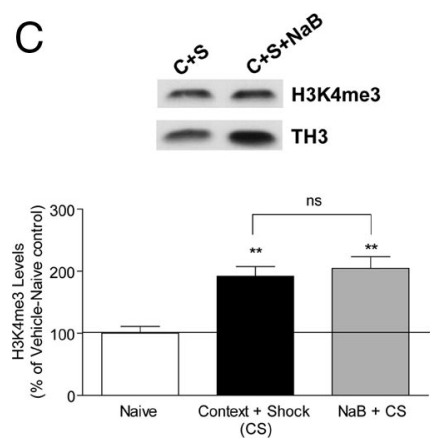

B
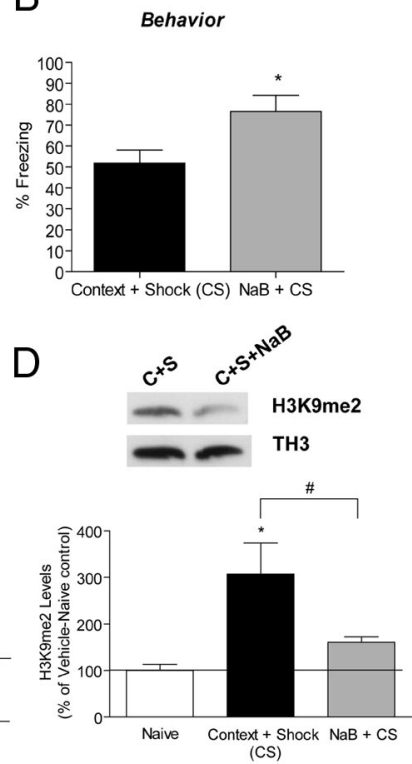

Figure 4. Inhibition of $\mathrm{HDAC}$ activity alters histone $\mathrm{H} 3$ trimethylation after contextual fear conditioning. $\boldsymbol{A}$, Experimental design is outlined with results displayed in $\boldsymbol{B}$ to $\boldsymbol{D}$. $\boldsymbol{B}, \mathrm{HDAC}$ inhibition with $\mathrm{NaB}$ treatment $1 \mathrm{~h}$ before fear conditioning $(\mathrm{NaB}+\mathrm{CS})$ increased freezing levels compared with vehicle-treated cohorts (Student's two-tailed $t$ test, $t_{(12)}=2.524, p=0.0267$, $n=7 /$ group). ${ }^{*} p$ value significant compared with vehicle-treated context plus shock alone. C, Histone H3 trimethylation (H3K4me3) levels slightly increased with NaB treatment when compared with vehicle-treated naive animal cohorts (one-way ANOVA with Tukey's multiplecomparison test, $F_{(2,11)}=13.64, p=0.0019, n=4 /$ group). ${ }^{* *} p<0.01$ compared with vehicle-treated naive controls, $\mathrm{ns}=$ not significant compared with (context plus shock; $C \mathrm{C}$ ). D, Dimethylated histone H3 (H3K9me2) levels significantly decreased with $\mathrm{NaB}$ treatment with fear conditioning ( $\mathrm{NaB}+\mathrm{CS}$ ) compared with vehicle-treated fear-conditioned animals (context plus shock; $(S)$ or vehicle-treated naive animal cohorts (one-way ANOVA with Tukey's multiple-comparison test, $F_{(2,11)}=7.199, p=0.0136, n=4 /$ group). ${ }^{*} p<0.05$ compared with naive controls, ${ }^{\#} p<0.05$ compared with context plus shock. Solid line represents normalized naive control levels. Error bars are SEM.

formation (Levenson et al., 2004a; Fischer et al., 2007; Lubin and Sweatt, 2007; Guan et al., 2009). We then assayed histone H3 methylation in area CA1 of hippocampus $1 \mathrm{~h}$ after training and found that both $\mathrm{NaB}$ - and vehicle-treated animals exposed to the fear conditioning paradigm displayed increased H3K4 trimethylation relative to naive animal controls (Fig. 4C). However, there was no significant difference in $\mathrm{H} 3 \mathrm{~K} 4$ trimethylation from $\mathrm{NaB}$ treated animals relative to that of vehicle-treated controls.

We next examined the effect of enhancing histone acetylation on $\mathrm{H} 3 \mathrm{~K} 9$ dimethylation in hippocampus following fear conditioning. We found that $\mathrm{NaB}$ treatment significantly decreased $\mathrm{H} 3 \mathrm{~K} 9$ dimethylation in hippocampus relative to vehicle-treated animals (Fig. 4D). These results suggest that elevating histone acetylation via HDAC inhibition leads to suppression of the negative regulator of transcription $\mathrm{H} 3 \mathrm{~K} 9$ dimethylation. This surprising result suggests that one mechanism whereby HDAC inhibition might enhance memory formation is through secondary suppression of histone H3K9 dimethylation. Regardless of this specific possibility, the result suggests a dynamic cross talk between histone acetylation and histone methylation in hippocampus.

Altered histone $\mathrm{H} 3$ trimethylation at specific gene promoters after contextual fear conditioning

To further support a role for histone methylation during memory formation, we determined whether fear conditioning triggers
A

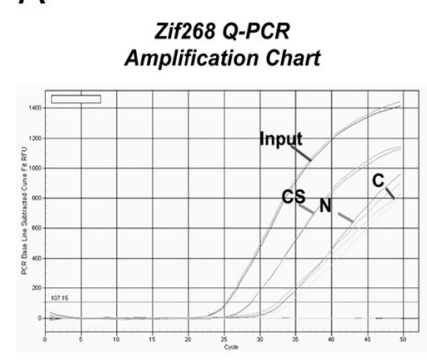

B ChIP: H3K4me3

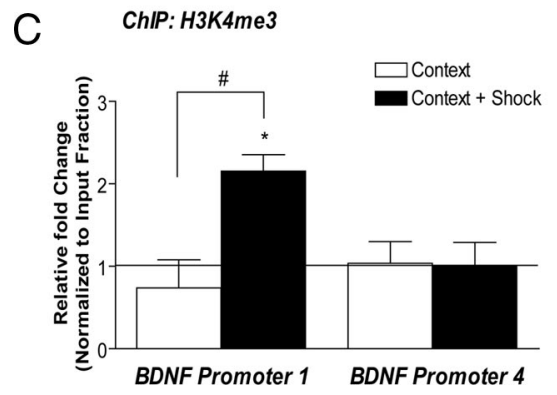

Figure 5. Contextual fear conditioning increases histone $\mathrm{H} 3$ trimethylation around the Zif268 and bdnf gene promoter. $\boldsymbol{A}$, Real-time PCR graph of histone $\mathrm{H} 3$ trimethylation (H3K4me3) ChIP samples. $\boldsymbol{B}$, Histone $\mathrm{H} 3$ trimethylation (H3K4me3) levels in area CA1 of hippocampus increase at the Zif268 promoter 30 min after fear conditioning (context plus shock; $\mathrm{CS})$ relative to context exposure $(\boldsymbol{C})$ or naive $(\boldsymbol{N})$ animals. (Student's two-tailed $t$ test, $t_{(6)}=$ 2.638, $p=0.0386, n=4$ /group). ${ }^{*} p<0.05$ compared with naive controls, ${ }^{\#} p<0.05$ compared with context exposure alone. $C$, Fear-conditioned animals demonstrated a significant increase in histone $\mathrm{H} 3$ trimethylation (H3K4me3) levels at bdnf promoter 1 (1-sample $t$ test, $t_{(4)}=5.714, p=0.0293, n=3-4$ /group). ${ }^{*} p<0.05$ compared with naive controls, ${ }^{\#} p<$ 0.05 compared with context exposure alone. At the time point assessed, there were no significant changes in histone $\mathrm{H} 3$ trimethylation (H3K4me3) levels at bdnf promoter 4 after fear conditioning. Solid line represents normalized naive control levels. Error bars are SEM.

changes in chromatin structure directly at the level of individual genes. The Zif 268 and $b d n f$ genes are critical for the consolidation of several forms of memories including hippocampus-dependent memory formation (Bramham, 2007; Poirier et al., 2007). Thus, we investigated hippocampal trimethylated H3K4 levels at the Zif268 and bdnf gene promoters $30 \mathrm{~min}$ after training, a time point known to be associated with transcriptional activation of these gene loci. Using ChIP assay combined with quantitative real-time PCR, we found that $\mathrm{H} 3 \mathrm{~K} 4$ trimethylation increased at the Zif268 promoter after fear conditioning (Fig. $5 A, B$ ). We also found that $\mathrm{H} 3 \mathrm{~K} 4$ trimethylation significantly increased at $b d n f$ promoter 1 , but not at promoter 4 , in area CA1 of hippocampus after fear conditioning, relative to naive controls (Fig. $5 C$ ). Context exposure alone produced no significant changes in $\mathrm{H} 3 \mathrm{~K} 4$ trimethylation at the Zif268 or $b d n f$ promoters relative to naive animal controls (Fig. 5A-C). The selective increase in histone trimethylation at the Zif 268 promoter and $b d n f$ promoter 1 is in good agreement with fear-conditioning-associated increased transcription of the Zif268 and bdnf genes (Lubin et al., 2008; Alberini, 2009). Together, these results demonstrate active regulation of $\mathrm{H} 3 \mathrm{~K} 4$ trimethylation within specific gene promoters, and further demonstrate that $\mathrm{H} 3 \mathrm{~K} 4$ trimethylation is regulated in response to fear conditioning.

Changes in DNA methylation are associated with altered histone methylation after fear conditioning

There is evidence that H3K9 dimethylation represses gene expression via recruitment of DNA methyltransferase enzymes, 
A

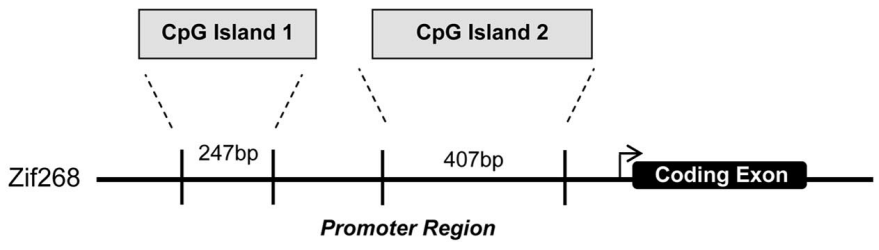

Zif268 DNA M ethylation Changes Associated with Histone Methylation

27342157-CTGTGAAGGAAGTGTTACCCTGAATT'1CGGG ${ }^{2} \mathrm{CGCCTTGGCAGTGG}^{3} \mathrm{CGGTTCCCT}^{4} \mathrm{CGGGACTG}^{5} \mathrm{CGG}$ GGAAGGCCCAGGC ${ }^{6} \mathrm{CGC}^{7} \mathrm{CG}^{8} \mathrm{CGCCTGCTCAGTTCTCCCTCACTG}^{9} \mathrm{CGTCTAAGGCTCTCCTGGCCTGGCTC}^{10} \mathrm{CG}^{11} \mathrm{CGCCCA}$ GCCCAGAAAGGGAGGGGGA ${ }^{12} \mathrm{CGTGGAGG}^{13} \mathrm{CGA}^{14} \mathrm{CGGAAGAGCC}^{15} \mathrm{CGC}^{16} \mathrm{CG}^{17} \mathrm{CGCCTGGGGCCCC}^{18} \mathrm{CG}$ GAATACAACCC GAGACCTCCAGAGGGCAGCAC ${ }^{19} \mathrm{CGAGCTGTAAG}^{20} \mathrm{CGCGCCCTCCGCATCGCAAGCCTGGGGTCACCAGACTGG-27342157}^{2}$

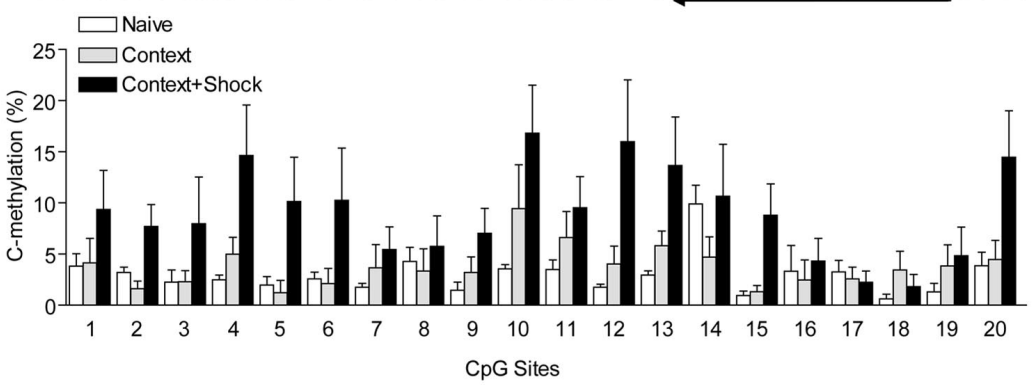

B Overall Zif268 DNA Methylation

\section{C}
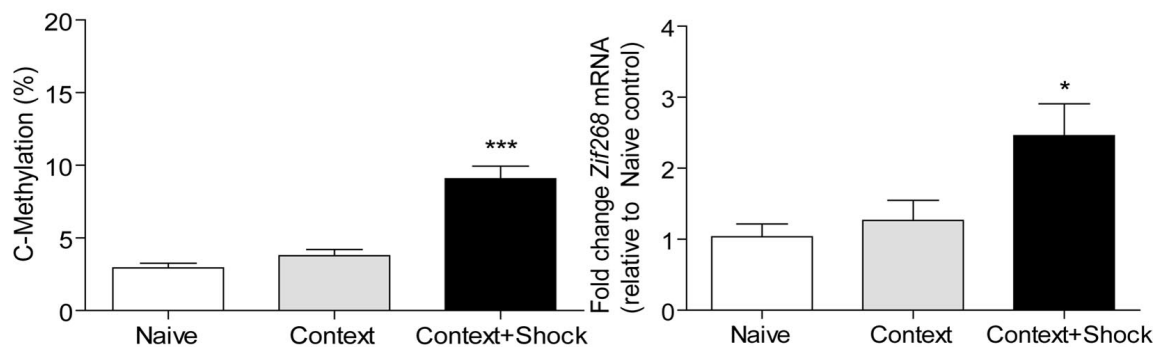

Figure 6. Increases in histone $\mathrm{H} 3$ trimethylation correlate with altered DNA methylation (Zif268 promoter) after fear conditioning. $\boldsymbol{A}$, Top, Methylation sites within CpG island 1 region of the Zif268 promoter. Sequencing primer pair positions are indicated by the left and right arrows. Methylation levels at the Zif268 promoter increased in area CA1 of hippocampus 30 min following fear conditioning (context plus shock) relative to context exposure (context) or naive animals (2-way ANOVA with Bonferroni's post hoc test; significant effect of behavior condition ( $F=18.51, p<0.0001, n=4-8 /$ group). $B$, Average percentage of DNA methylation across the Zif268 promoter ( $\mathrm{CpG}$ island 1) in area CA1 of hippocampus after fear conditioning (context plus shock) compared with context exposure (context) or naive animals. ${ }^{* *} p<0.001$ compared with naive controls. $C$, Although surprising, after training Zif268 gene expression remained significantly elevated with increased DNA methylation (context plus shock) (1-samplettest, $t_{(5)}=3.238$, $p=0.023, n=3-6 /$ group). ${ }^{*} p<0.05$ compared with naive controls. Error bars are SEM.

which mediate methylation of $\mathrm{CpG}$ dinucleotides that then recruit repressive chromatin remodeling complexes (Fuks, 2005). In contrast to $\mathrm{H} 3 \mathrm{~K} 9$ dimethylation, $\mathrm{H} 3 \mathrm{~K} 4$ trimethylation mediates active transcription and shows a strong correlation with activated RNA polymerase II and histone acetylation levels at gene promoters (Rice and Futscher, 2000; Nakayama et al., 2001; Rice and Allis, 2001; Li and Zhang, 2004; Zhang et al., 2004; Ruthenburg et al., 2007). Thus, given our finding that H3K4 trimethylation is increased after fear conditioning, we next determined whether or not DNA methylation was altered during memory consolidation in a manner that was indicative of an active promoter. Consistent with this idea, we previously have reported that $b d n f$ promoter 1 shows decreased cytosine (DNA) methylation with contextual fear conditioning (Lubin et al., 2008). These previous findings are in good agreement with the idea that $\mathrm{H} 3 \mathrm{~K} 4$ trimethylation levels at $b d n f$ promoter 1 (Fig. $5 C$ ) correlates with DNA demethylation during fear conditioning. However, we also previously observed that fear conditioning is associated with decreased DNA methylation at $b d n f$ exon 4 at $2 \mathrm{~h}$ post-training (Lubin et al., 2008), but this site did not manifest increased histone methylation (at 30 min post-training) in the current studies (Fig. 5C). Thus, the available evidence does not allow us to ascertain whether $\mathrm{H} 3 \mathrm{~K} 4$ trimethylation is universally correlated with DNA demethylation in the adult CNS.

Therefore in the present studies, we performed additional experiments and examined the DNA methylation state of the Zif268 promoter because increases in $\mathrm{H} 3 \mathrm{~K} 4$ trimethylation levels in hippocampus were robust at this promoter region in response to associative contextual fear conditioning (Fig. 5B). Furthermore, unlike $b d n f$ DNA methylation (Lubin et al., 2008), the methylation state of the Zif268 gene has not been previously characterized in hippocampus during memory formation.

We first screened the Zif268 promoter region for $\mathrm{CpG}$ islands, which are defined as stretches of DNA ( $1200 \mathrm{bp})$ in which there are a large number of cytosine-guanine dinucleotide sequences linked by phosphodiester bonds (for review, see Goldberg et al., 2007). Using Methprimer software (http://www.urogene. org/methprimer/) (Li and Dahiya, 2002) two $\mathrm{CpG}$ island sites were found within the promoter region of the Zif268 gene immediately preceding the transcriptional start site (Fig. 6A). We first used MSP to screen DNA methylation changes at each $\mathrm{CpG}$ island site $30 \mathrm{~min}$ following fear conditioning. Our MSP results demonstrated that fear conditioning triggered changes in DNA methylation at CpG island region 1 , but not region 2 , in hippocampus (data not shown).

Next, we used direct BSP to examine site-specific methylation changes at 20 CpG dinucleotides within Zif268 CpG island region 1 (Fig. $6 A$ ). The results show that fear conditioning elicited an increase in methylated DNA levels across the region relative to context exposure alone or naive animal controls (Fig. $6 \mathrm{~B}$ ). However, Zif268 mRNA levels $30 \mathrm{~min}$ after training were significantly increased in hippocampus in response to fear conditioning (Fig. 6C). Thus, these results suggest that increased $\mathrm{H} 3 \mathrm{~K} 4$ trimethylation levels at the Zif268 promoter is associated with increases in DNA methylation resulting in active transcription of the Zif268 gene after fear conditioning. Overall these data support the idea that $\mathrm{H} 3 \mathrm{~K} 4$ trimethylation can be associated with either increased DNA methylation (Zif268), or decreased DNA methylation $(b d n f)$ at genes that are transcriptionally activated in memory consolidation.

Next, we sought to determine the effect of contextual fear conditioning on Zif268 DNA methylation 24 h later. We found that $Z$ if 268 DNA methylation and mRNA levels returned to baseline $24 \mathrm{~h}$ after fear conditioning compared with naive controls (Fig. 7A-C). This suggests that the effect of contextual fear conditioning on Zif268 DNA methylation was also transient. Inter- 
estingly, we also observed an increase in Zif268 DNA methylation $24 \mathrm{~h}$ after exposure to context alone compared with naive animal controls (Fig. 7A), which corresponds with a decrease in Zif268 gene expression $24 \mathrm{~h}$ after context exposure alone (Fig. 7B). These data support the idea that altered DNA methylation can be associated with either increased Zif268 gene expression $30 \mathrm{~min}$ after fear memory consolidation or decreased Zif268 gene expression $24 \mathrm{~h}$ after context exposure.

Although the findings of increased DNA methylation associated with increase Zif268 gene transcription with contextual fear conditioning were surprising, they are consistent with previous results by Chahrour et al. (2008) suggesting that methyl-binding proteins such as methyl-CpG binding protein 2 (MeCP2) can activate as well as repress gene transcription, specifically suggesting that $\mathrm{MeCP} 2$ associates with the transcriptional activator CREB1 at methylated promoter regions of activated gene target. Thus, we sought to determine whether or not the effect of contextual fear conditioning on Zif268 DNA methylation was associated with altered MeCP2 levels at the gene promoter. We found that MeCP2 significantly decreased at the Zif268 promoter region associated with increased $\mathrm{H} 3 \mathrm{~K} 4$ trimethylation $30 \mathrm{~min}$ after fear conditioning or context exposure compared with naive controls (Fig. 8A) (ChIP1). These results indicate that learning about the context or fear conditioning to the context has effects on the recruitment of MeCP2 levels at the Zif268 promoter in hippocampus. We also observed an increase in MeCP2 at the Zif268 promoter region associated with increased DNA methylation 30 min after fear conditioning, but not after exposure to context alone, compared with naive animal controls (Fig. 8B) (ChIP2). Thus, Zif268 mRNA levels $30 \mathrm{~min}$ after training were significantly increased in hippocampus in response to fear conditioning (Fig. 6C). Together, these findings are consistent with the idea that increases in DNA methylation can represent an active signal for gene transcription.

\section{Discussion}

In the studies presented here, we investigated the potential role of histone lysine methylation in memory formation and established several findings. First, we found that fear conditioning triggers changes in $\mathrm{H} 3 \mathrm{~K} 4$ trimethylation (a transcriptional active marker) and $\mathrm{H} 3 \mathrm{~K} 9$ dimethylation (a transcriptional repressive marker) in area CA1 of the hippocampus. Second, we observed that H3K4specific methyltransferase $(M l l)$-deficient mice have a deficit in long-term memory formation. Third, treatment of animals with the HDAC inhibitor $\mathrm{NaB}$ altered histone methylation levels in hippocampus during memory consolidation, suggesting that altered histone methylation is coupled to HDAC inhibition. Finally, H3K4 trimethylation significantly increased at the promoter of two activated gene targets (Zif268 and bdnf) during memory consolidation. Together, these findings support the role of histone methylation changes in the consolidation of long-term memory formation.

Covalent post-translational modifications of histones serve as an important mechanism for transcriptional regulation during consolidation of long-term memories. For example, increases in histone $\mathrm{H} 3$ phosphorylation and acetylation in hippocampus have been shown to be regulated during long-term memory formation (Levenson et al., 2004a; Chwang et al., 2006; Fischer et al., 2007). Additionally, regulation of histone modifications including histone methylation have been implicated in mental disorders including schizophrenia (Deutsch et al., 2008; Akbarian and Huang, 2009). However, investigation of the role of histone 
B

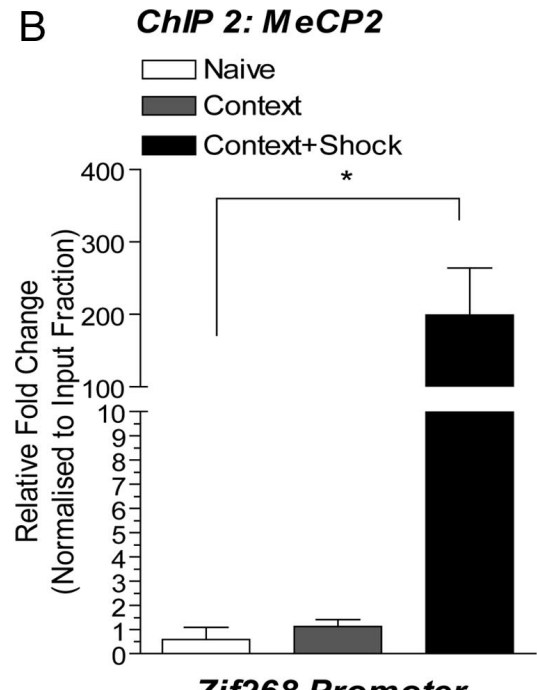

Zif268 Promoter

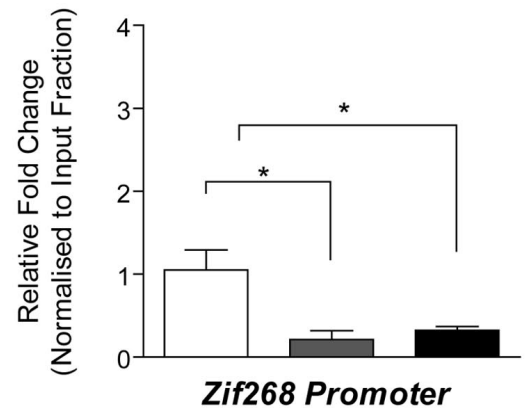

C

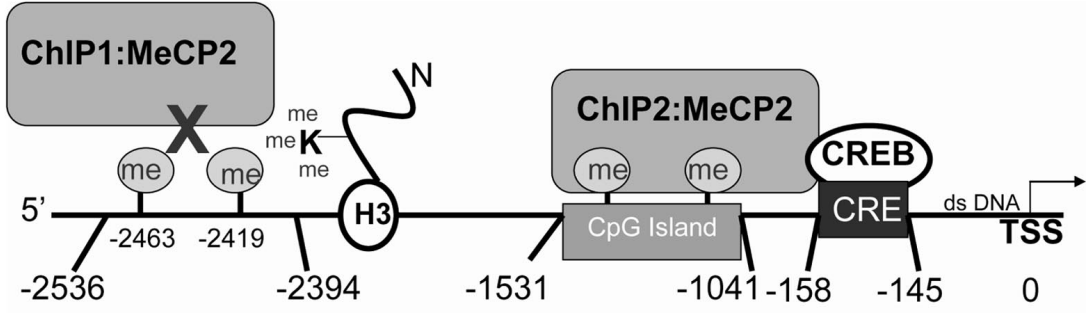

Figure 8. Contextual fear conditioning triggers altered MeCP2 levels around the Zif268 gene promoter. $A$, MeCP2 levels in area CA1 of hippocampus decrease at the Zif268 promoter region that corresponds with increased histone H3 trimethylation (ChIP 1) 30 min after fear conditioning (context plus shock) relative to context exposure (context) or naive animals (1-sample $t$ test, $t_{(3)}=$ $7.402, p=0.0051, n=3-4 /$ group). ${ }^{*} p<0.05$ compared with naive controls. $\boldsymbol{B}$, Fear-conditioned animals demonstrated a significant increase in MeCP2 levels at the Zif268 promoter region that corresponds with increased DNA methylation (ChIP 2) 30 min after fear conditioning (context plus shock) relative to naive animals (1-sample $t$ test, $t_{(3)}=5.412, p=0.0124, n=$ $3-4 /$ group). ${ }^{*} p<0.05$ compared with naive controls. At the time point assessed, there were no significant changes in MeCP2 levels at Zif268 promoter after context exposure (context) relative to naive animals. Error bars are SEM. C, Schematic: Proposed mechanism on how the chromatin microenvironment at the Zif268 promoter regulates its expression; following contextual fear conditioning, an enhancement in histone $\mathrm{H} 3$ lysine 4 trimethylation is observed upstream of the transcription start site (TSS) coinciding with a reduction in MeCP2 DNA binding (ChIP1). At CpG island 1 (Fig. 6), increased DNA methylation is associated with increased MeCP2 binding (ChIP 2). We postulate that MeCP2 associated with CpG island 1 interacts with CREB bound to a cAMP response element (CRE) site situated near the TSS. This interaction allows increased transcription of the Zif268 gene during long-term memory formation. Me CP2, Methyl CpG binding protein; me, methyl groups; CREB, CAMP response element binding protein; ds-DNA, double-stranded DNA.

methylation in the process of long-term memory formation had not been explored before the current studies. Encouragingly, studies on abnormal gene expression in postmortem brain have revealed that histone methylation may be a viable avenue for early detection for some cases of schizophrenia (Akbarian and Huang, 2009). Therefore, the study of histone methylation in the regulation of memory formation is intriguing and will provide further insights into the epigenetic mechanisms that may be dysregulated in cognitive impairments.

We investigated the contribution of hippocampal histone methylation in the consolidation of long-term memory in a rodent model of fear conditioning. We were particularly interested in studying this form of histone modification because it is unique in that various specific sites of methylation of histones can have opposite roles in gene regulation; that is, methylation of $\mathrm{H} 3 \mathrm{~K} 4$ is associated with active transcription whereas methylation of H3K9 is associated with transcriptional silencing (Strahl et al., 1999; Lachner and Jenuwein, 2002; Schotta et al., 2002). Indeed, the process of storing stable long-term memories is likely to in- volve coordinated changes in both transcriptional activation and silencing of genes (Ressler et al., 2002; Levenson et al., 2004b). Now with the results presented here, we provide the first evidence for histone methylation changes in hippocampus in response to contextual learning, in both episodic learning and associative contextual fear conditioning. Furthermore, these results support the hypothesis that histone methylation plays a role in the regulation of gene expression changes that are permissive for memory formation.

One fascinating finding from our studies is that HDAC inhibition significantly altered histone methylation levels. Specifically, treatment with the nonselective class I HDAC inhibitor $\mathrm{NaB}$ significantly attenuated H3K9 dimethylation in hippocampus after fear conditioning. This suggests the new idea that a possible mechanism for the permissive actions of inhibiting HDACs, resulting in memory enhancement, is through the negative regulation of hippocampal H3K9 dimethylation. However, the specific HDAC isoform(s) inhibited by the HDAC inhibitor $\mathrm{NaB}$ to mediate this effect on $\mathrm{H} 3 \mathrm{~K} 9$ dimethylation is unknown and remains an intriguing focus of ongoing studies. Promisingly, the HDAC2 isoform has recently been identified as a modulator of dendritic spine density, synapse number, and synaptic plasticity which negatively regulates memory formation (Guan et al., 2009). Although very speculative at this point, an intriguing hypothesis is that inhibition of HDAC2 negatively regulates $\mathrm{H} 3 \mathrm{~K} 9$ dimethylation to allow memory enhancement. Whether this scenario is true or not, our present study is consistent with the idea that inhibition of HDAC isoforms promotes active gene transcription for stable formation of enhanced longterm memories.

Another remarkable finding from these studies is that changes in $\mathrm{H} 3 \mathrm{~K} 4$ trimethylation were associated with increased DNA methylation at the Zif268 promoter region, while Zif268 gene expression was active during memory consolidation. In addition, these changes in Zif268 DNA methylation were transient returning to baseline levels $24 \mathrm{~h}$ later long after the consolidation period. These observations are in sharp contrast to findings from developmental studies that suggest that DNA methylation is primarily associated with the repression of gene transcription. However, a recent study by Chahrour et al. (2008) indicates that methyl-CpG binding proteins, such as MeCP2, bind to DNA methylation sites with the transcriptional activator cyclic adenosine monophosphate (CAMP) response element binding (CREB) protein 1 to actively regulate gene transcription. Indeed, our results suggest that MeCP2 levels increased at the Zif268 promoter region in association with increased DNA methylation resulting in transcriptional activation of the Zif268 gene following fear conditioning. Correspondingly, we found a cAMP response element (CRE; TCACGTCA) binding site for the transcription fac- 
tor CREB downstream of the $\mathrm{CpG}$ island 1 region and upstream from the transcriptional start site of the Zif268 gene (Fig. 8C). Thus, based on previous studies by Chahrour et al. (2008) and our present data, we propose that dynamic changes in DNA methylation may serve as both a repressive or active marker of transcription in hippocampus during long-term memory formation. This new concept raises several intriguing possibilities for future research. For example, in our study we demonstrated that contextual learning induces global changes in histone methylation as well as altered DNA methylation. However, it remains to be determined what specific cell types are involved in these observed epigenetic mechanisms.

In summary, our results continue to support a role for epigenetic mechanisms in the process of stable formation of long-term memories. Specifically, our findings demonstrate considerable histone methylation changes in hippocampus in association with memory formation and furthermore suggest that this process is necessary for long-term memory formation. In addition our results provide the first evidence for an association between differential histone methylation and DNA methylation regulation at the Zif268 gene promoter in the adult brain and implicate a possible role for these processes in the formation of long-term memories. Finally, as epigenetic mechanisms continue to be linked to cognitive dysfunctions a better understanding of the complex molecular interaction and regulation of these processes will need to be further refined.

The importance of continued investigation of such mechanisms is underscored by several prior studies. For example, similar to DNA methylation, histone methylation was once considered to be a nonplastic process. The concept of the irreversibility of histone methylation arose from the belief that histone demethylases did not exist. However, this view has recently been challenged with the identification of several histone H3 demethylases including LSD1 and JHDM1 (Shi et al., 2004; Tsukada et al., 2006; Whetstine et al., 2006; Tahiliani et al., 2007) which can specifically demethylate lysine-4 within histone H3. Thus, the discovery of these enzymes may lead to more selective therapeutic interventions that include the use of histone demethylase activators or inhibitors as well as HDAC inhibitors for treatment of cognitive impairments associated with neurological disorders.

\section{References}

Akbarian S, Huang HS (2009) Epigenetic regulation in human brain-focus on histone lysine methylation. Biol Psychiatry 65:198-203.

Alarcón JM, Malleret G, Touzani K, Vronskaya S, Ishii S, Kandel ER, Barco A (2004) Chromatin acetylation, memory, and LTP are impaired in CBP $+/-$ mice: a model for the cognitive deficit in Rubinstein-Taybi syndrome and its amelioration. Neuron 42:947-959.

Alberini CM (2009) Transcription factors in long-term memory and synaptic plasticity. Physiol Rev 89:121-145.

Allis CD, Berger SL, Cote J, Dent S, Jenuwien T, Kouzarides T, Pillus L, Reinberg D, Shi Y, Shiekhattar R, Shilatifard A, Workman J, Zhang Y (2007) New nomenclature for chromatin-modifying enzymes. Cell 131:633-636.

Atkins CM, Selcher JC, Petraitis JJ, Trzaskos JM, Sweatt JD (1998) The MAPK cascade is required for mammalian associative learning. Nat Neurosci 1:602-609.

Berger SL (2007) The complex language of chromatin regulation during transcription. Nature 447:407-412.

Bramham CR (2007) Control of synaptic consolidation in the dentate gyrus: mechanisms, functions, and therapeutic implications. Prog Brain Res 163:453-471.

Bredy TW, Wu H, Crego C, Zellhoefer J, Sun YE, Barad M (2007) Histone modifications around individual BDNF gene promoters in prefrontal cortex are associated with extinction of conditioned fear. Learn Mem 14:268-276.

Chahrour M, Jung SY, Shaw C, Zhou X, Wong ST, Qin J, Zoghbi HY (2008) $\mathrm{MeCP} 2$, a key contributor to neurological disease, activates and represses transcription. Science 320:1224-1229.

Chwang WB, O'Riordan KJ, Levenson JM, Sweatt JD (2006) ERK/MAPK regulates hippocampal histone phosphorylation following contextual fear conditioning. Learn Mem 13:322-328.

Colvis CM, Pollock JD, Goodman RH, Impey S, Dunn J, Mandel G, Champagne FA, Mayford M, Korzus E, Kumar A, Renthal W, Theobald DE, Nestler EJ (2005) Epigenetic mechanisms and gene networks in the nervous system. J Neurosci 25:10379-10389.

Deutsch SI, Rosse RB, Mastropaolo J, Long KD, Gaskins BL (2008) Epigenetic therapeutic strategies for the treatment of neuropsychiatric disorders: ready for prime time? Clin Neuropharmacol 31:104-119.

Fischer A, Sananbenesi F, Wang X, Dobbin M, Tsai LH (2007) Recovery of learning and memory is associated with chromatin remodelling. Nature 447:178-182.

Fuks F (2005) DNA methylation and histone modifications: teaming up to silence genes. Curr Opin Genet Dev 15:490-495.

Goldberg AD, Allis CD, Bernstein E (2007) Epigenetics: a landscape takes shape. Cell 128:635-638.

Guan JS, Haggarty SJ, Giacometti E, Dannenberg JH, Joseph N, Gao J, Nieland TJ, Zhou Y, Wang X, Mazitschek R, Bradner JE, DePinho RA, Jaenisch R, Tsai LH (2009) HDAC2 negatively regulates memory formation and synaptic plasticity. Nature 459:55-60.

Guan Z, Giustetto M, Lomvardas S, Kim JH, Miniaci MC, Schwartz JH, Thanos D, Kandel ER (2002) Integration of long-term-memory-related synaptic plasticity involves bidirectional regulation of gene expression and chromatin structure. Cell 111:483-493.

Huang HS, Akbarian S (2007) GAD1 mRNA expression and DNA methylation in prefrontal cortex of subjects with schizophrenia. PLoS One 2:e809.

Huang HS, Matevossian A, Whittle C, Kim SY, Schumacher A, Baker SP, Akbarian S (2007) Prefrontal dysfunction in schizophrenia involves mixed-lineage leukemia 1-regulated histone methylation at GABAergic gene promoters. J Neurosci 27:11254-11262.

Kim SY, Levenson JM, Korsmeyer S, Sweatt JD, Schumacher A (2007) Developmental regulation of Eed complex composition governs a switch in global histone modification in brain. J Biol Chem 282:9962-9972.

Kumar A, Choi KH, Renthal W, Tsankova NM, Theobald DE, Truong HT, Russo SJ, Laplant Q, Sasaki TS, Whistler KN, Neve RL, Self DW, Nestler EJ (2005) Chromatin remodeling is a key mechanism underlying cocaineinduced plasticity in striatum. Neuron 48:303-314.

Kuzmichev A, Jenuwein T, Tempst P, Reinberg D (2004) Different EZH2containing complexes target methylation of histone $\mathrm{H} 1$ or nucleosomal histone H3. Mol Cell 14:183-193.

Lachner M, Jenuwein T (2002) The many faces of histone lysine methylation. Curr Opin Cell Biol 14:286-298.

Levenson JM, Sweatt JD (2005) Epigenetic mechanisms in memory formation. Nat Rev Neurosci 6:108-118.

Levenson JM, O’Riordan KJ, Brown KD, Trinh MA, Molfese DL, Sweatt JD (2004a) Regulation of histone acetylation during memory formation in the hippocampus. J Biol Chem 279:40545-40559.

Levenson JM, Choi S, Lee SY, Cao YA, Ahn HJ, Worley KC, Pizzi M, Liou HC, Sweatt JD (2004b) A bioinformatics analysis of memory consolidation reveals involvement of the transcription factor c-rel. J Neurosci 24:3933-3943.

Li LC, Dahiya R (2002) MethPrimer: designing primers for methylation PCRs. Bioinformatics 18:1427-1431.

Li X, Zhang FX (2004) [On the research of histone methylation.] Yi Chuan 26:244-248.

Livak KJ, Schmittgen TD (2001) Analysis of relative gene expression data using real-time quantitative PCR and the 2(-delta delta C(T)) method. Methods 25:402-408.

Lubin FD, Sweatt JD (2007) The IkappaB kinase regulates chromatin structure during reconsolidation of conditioned fear memories. Neuron 55:942-957.

Lubin FD, Ren Y, Xu X, Anderson AE (2007) Nuclear factor-kappa B regulates seizure threshold and gene transcription following convulsant stimulation. J Neurochem 103:1381-1395.

Lubin FD, Roth TL, Sweatt JD (2008) Epigenetic regulation of BDNF gene 
transcription in the consolidation of fear memory. J Neurosci 28:10576-10586.

Lubow RE, Josman ZE (1993) Latent inhibition deficits in hyperactive children. J Child Psychol Psychiatry 34:959-973.

Margueron R, Trojer P, Reinberg D (2005) The key to development: interpreting the histone code? Curr Opin Genet Dev 15:163-176.

Martin C, Zhang Y (2005) The diverse functions of histone lysine methylation. Nat Rev Mol Cell Biol 6:838-849.

McIlwain KL, Merriweather MY, Yuva-Paylor LA, Paylor R (2001) The use of behavioral test batteries: effects of training history. Physiol Behav 73:705-717.

Milne TA, Briggs SD, Brock HW, Martin ME, Gibbs D, Allis CD, Hess JL (2002) MLL targets SET domain methyltransferase activity to Hox gene promoters. Mol Cell 10:1107-1117.

Nakayama J, Rice JC, Strahl BD, Allis CD, Grewal SI (2001) Role of histone $\mathrm{H} 3$ lysine 9 methylation in epigenetic control of heterochromatin assembly. Science 292:110-113.

Ng HH, Robert F, Young RA, Struhl K (2003) Targeted recruitment of Set1 histone methylase by elongating Pol II provides a localized mark and memory of recent transcriptional activity. Mol Cell 11:709-719.

Paylor R, Tracy R, Wehner J, Rudy JW (1994) DBA/2 and C57BL/6 mice differ in contextual fear but not auditory fear conditioning. Behav Neurosci 108:810-817.

Paylor R, Spencer CM, Yuva-Paylor LA, Pieke-Dahl S (2006) The use of behavioral test batteries, II: effect of test interval. Physiol Behav 87:95-102.

Peterson CL, Laniel MA (2004) Histones and histone modifications. Curr Biol 14:R546-R551.

Poirier R, Cheval H, Mailhes C, Charnay P, Davis S, Laroche S (2007) Paradoxical role of an egr transcription factor family member, egr $2 / \mathrm{krox} 20$, in learning and memory. Front Behav Neurosci 1:6.

Ressler KJ, Paschall G, Zhou XL, Davis M (2002) Regulation of synaptic plasticity genes during consolidation of fear conditioning. J Neurosci 22:7892-7902.

Rice JC, Allis CD (2001) Histone methylation versus histone acetylation: new insights into epigenetic regulation. Curr Opin Cell Biol 13:263-273.

Rice JC, Futscher BW (2000) Transcriptional repression of BRCA1 by aberrant cytosine methylation, histone hypoacetylation and chromatin condensation of the BRCA1 promoter. Nucleic Acids Res 28:3233-3239.

Ruthenburg AJ, Allis CD, Wysocka J (2007) Methylation of lysine 4 on histone H3: intricacy of writing and reading a single epigenetic mark. Mol Cell 25:15-30.

Santos-Rosa H, Schneider R, Bannister AJ, Sherriff J, Bernstein BE, Emre NC, Schreiber SL, Mellor J, Kouzarides T (2002) Active genes are trimethylated at K4 of histone H3. Nature 419:407-411.

Schneider R, Bannister AJ, Myers FA, Thorne AW, Crane-Robinson C, Kouzarides T (2004) Histone H3 lysine 4 methylation patterns in higher eukaryotic genes. Nat Cell Biol 6:73-77.

Schotta G, Ebert A, Krauss V, Fischer A, Hoffmann J, Rea S, Jenuwein T, Dorn R, Reuter G (2002) Central role of Drosophila SU(VAR)3-9 in histone
H3-K9 methylation and heterochromatic gene silencing. EMBO J 21:1121-1131.

Schumacher A, Faust C, Magnuson T (1996) Positional cloning of a global regulator of anterior-posterior patterning in mice. Nature 384:648.

Shi Y, Lan F, Matson C, Mulligan P, Whetstine JR, Cole PA, Casero RA, Shi Y (2004) Histone demethylation mediated by the nuclear amine oxidase homolog LSD1. Cell 119:941-953.

Sims RJ 3rd, Nishioka K, Reinberg D (2003) Histone lysine methylation: a signature for chromatin function. Trends Genet 19:629-639.

Strahl BD, Ohba R, Cook RG, Allis CD (1999) Methylation of histone H3 at lysine 4 is highly conserved and correlates with transcriptionally active nuclei in Tetrahymena. Proc Natl Acad Sci U S A 96:14967-14972.

Swank MW, Sweatt JD (2001) Increased histone acetyltransferase and lysine acetyltransferase activity and biphasic activation of the ERK/RSK cascade in insular cortex during novel taste learning. J Neurosci 21:3383-3391.

Tahiliani M, Mei P, Fang R, Leonor T, Rutenberg M, Shimizu F, Li J, Rao A, Shi Y (2007) The histone H3K4 demethylase SMCX links REST target genes to X-linked mental retardation. Nature 447:601-605.

Tsankova NM, Berton O, Renthal W, Kumar A, Neve RL, Nestler EJ (2006) Sustained hippocampal chromatin regulation in a mouse model of depression and antidepressant action. Nat Neurosci 9:519-525.

Tsukada Y, Fang J, Erdjument-Bromage H, Warren ME, Borchers $\mathrm{CH}$, Tempst P, Zhang Y (2006) Histone demethylation by a family of JmjC domain-containing proteins. Nature 439:811-816.

van der Vlag J, Otte AP (1999) Transcriptional repression mediated by the human polycomb-group protein EED involves histone deacetylation. Nat Genet (1999) 23:474-478.

Vermeulen M, Mulder KW, Denissov S, Pijnappel WW, van Schaik FM, Varier RA, Baltissen MP, Stunnenberg HG, Mann M, Timmers HT (2007) Selective anchoring of TFIID to nucleosomes by trimethylation of histone H3 lysine 4. Cell 131:58-69.

Whetstine JR, Nottke A, Lan F, Huarte M, Smolikov S, Chen Z, Spooner E, Li E, Zhang G, Colaiacovo M, Shi Y (2006) Reversal of histone lysine trimethylation by the JMJD2 family of histone demethylases. Cell 125: 467-481.

Wood MA, Attner MA, Oliveira AM, Brindle PK, Abel T (2006) A transcription factor-binding domain of the coactivator CBP is essential for longterm memory and the expression of specific target genes. Learn Mem 13:609-617.

Yu BD, Hess JL, Horning SE, Brown GA, Korsmeyer SJ (1995) Altered Hox expression and segmental identity in Mll-mutant mice. Nature 378: 505-508.

Zhang K, Siino JS, Jones PR, Yau PM, Bradbury EM (2004) A mass spectrometric Western blot to evaluate the correlations between histone methylation and histone acetylation. Proteomics 4:3765-3775.

Xia ZB, Anderson M, Diaz MO, Zeleznik-Le NJ (2003) MLL repression domain interacts with histone deacetylases, the polycomb group proteins HPC2 and BMI-1, and the corepressor C-terminal-binding protein. Proc Natl Acad Sci U S A 100:8342-8347. 